\title{
The evaluation of the surface quality after laser cutting
}

\author{
Tomáš Zlámal ${ }^{1, *}$, Šárka Malotová ${ }^{1}$, Jana Petrů $^{1}$, Zbigniew Brytan $^{2}$, and Václav Musil ${ }^{1}$ \\ ${ }^{1}$ VŠB - Technical University of Ostrava, Faculty of Mechanical Engineering, 17. listopadu 15/2172, \\ Ostrava - Poruba, 708 33, Czech Republic \\ ${ }^{2}$ Instytut Materiałów Inżynierskich i Biomedycznych, Konarskiego 18a, 44-100 Gliwice, Poland
}

\begin{abstract}
The contribution deals with the evaluation of the surface quality after laser cutting and determination of the influence individual input laser parameters at the whole process. There were selected samples for experiment made from S235JR material with the thickness $10 \mathrm{~mm}$ and $15 \mathrm{~mm}$. There was set up values of process parameters, such as laser power, focal spot position, cutting speed and shield gas pressure. The final surface quality was measured and evaluated on the basis of the selected surface roughness parameters and material ratio. The surface quality was evaluated from point of view of defects emerging after thermal splitting according to standard ČSN EN ISO 17658 .
\end{abstract}

Keywords: Laser Cutting; Cutting Parameters; Surface Roughness, Abbott-Firestone Curve.

\section{Introduction}

Currently, there is the development of non-conventional methods of machining including of the laser cutting technology which has width use in most key industry. The laser technology brings many benefits including of high accuracy, low running costs, quiet operation, zero wear of cutting tool, sharp edges, relatively small heat-affected area and especially width range of cut materials, metal or non-metallic material in comparison with conventional methods of chipping machining. In the past, there were realized several researches focused on laser cutting whether for steel, non-ferrous material, heavy machinable or plastic materials and their influence on the surface quality $[1,2,3]$.

The cut quality is influenced especially by input parameters, choice of cut material and its thickness, structure or homogeneity. The laser cutting process is very complicated, therefore setting of the parameters such as laser power, shield gas pressure, cutting speed and focal spot position can significantly influence final cut quality. The right combination of these parameters can achieve reduction or even total prevention amount of defects emerging after thermal splitting. The defects, such as slides, melting of upper edge, presence of iron scales, burrs etc. have significantly impact on the evaluate surface from the point of view of surface roughness and material ratio which is characterized by Abbott-Firestone curve [4].

\footnotetext{
* Corresponding author: tomas.zlamal@vsb.cz

Reviewers: Anna Rudawska, Michal Hatala
} 
It is important to focus on the final surface roughness and values of core roughness $\mathrm{Rk}$, reduced peak height Rpk and reduced valley depth Rvk. The results of measuring help to predict surface in area of development of cracks, amount of protrusions and recesses which have the influence on primary wear, final life-time of surface cut sample and enable preset of input parameters which ensure higher cut quality [5].

\section{The factors influencing laser cutting}

As mentioned above, it is necessary to set the process parameteres with regards on selected material and its thickness in order to ensure sufficient cut quality. Incorrect setting of parameters can cause reduction of cut quality and presence of burrs, heat, etc. The evaluation of cut quality after laser cutting occurs in technical publications $[6,7,8]$. In these publication the authors mention the parameters, such as cutting speed, focal spot position, shield gas pressure or laser power and their influence on the surface quality. It is necessary to set sufficient laser power with regard to the material thickness which ensure its total separation for laser cutting. It is important that the value of the laser power was constant during the cutting time and allow to get the best cut quality combined with other set input cutting parameters. The low value of laser power causes significantly worsening of surface quality in the bottom part of the cut (tab. 1). In case of incorrect set (high value) of cutting speed may occur incomplete separation of material or by contrast it may cause worsening of surface roughness and pulling out material on the bottom edge. Just as laser power, the cutting speed has to be adapted to the type and thickness of material. Incorrect selected cutting speed can cause high value of surface roughness and origin burrs, it leads to a poor quality cut $[9,10]$. In table 1, there are show of decreased of the cut quality caused unsuitable set cutting parameters.

Table 1 Cutting quality with different settings [11]

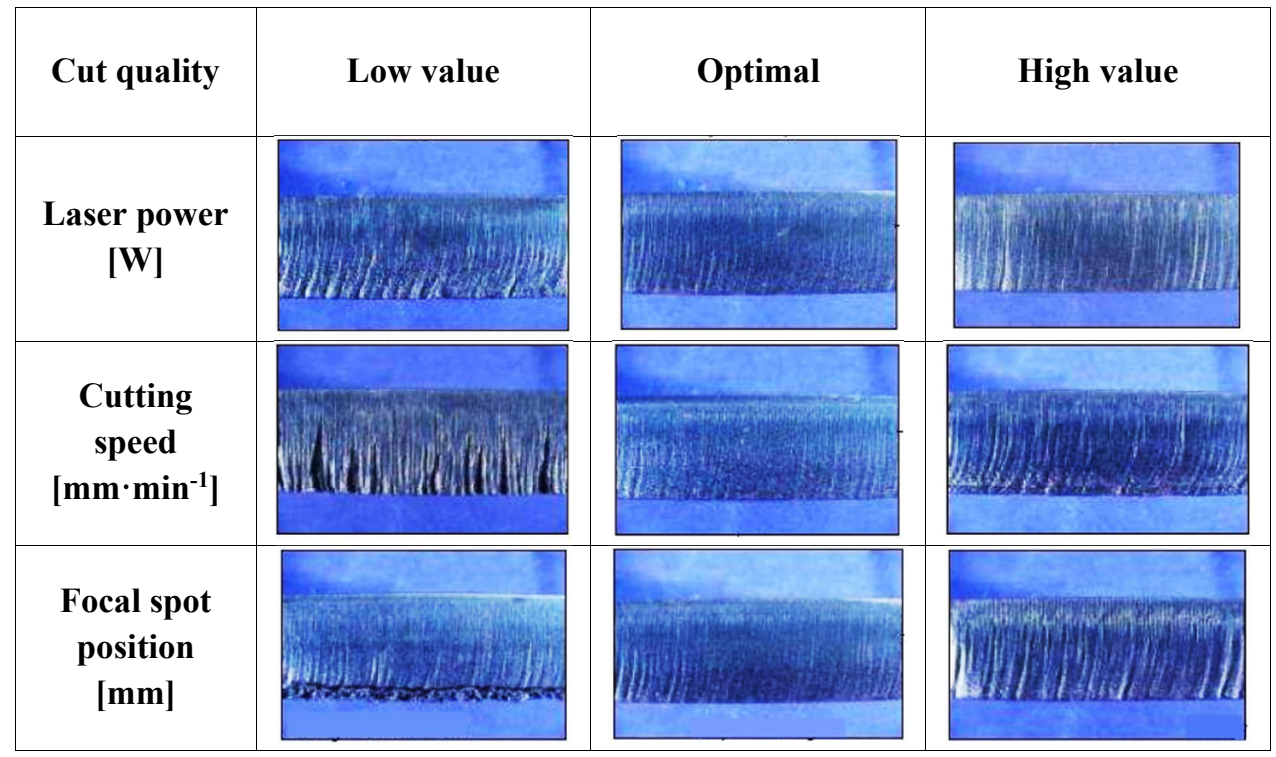

The next tracked parameters are focal spot position and shield gas pressure. If the focal spot position is set too near to the material, there can be created burrs on the bottom edge of the cut. In the opposite case, larger position causes worsened surface roughness and cut 
quality. The focal spot position is connected with its nozzle standoff height which is determine with regards on the material thickness and type of cutting. The shield gas pressure has an influence on the cut quality, surface roughness and origin of burrs. The shield gas pressure is necessary adapt to the material thickness. The function of shield gas pressure is to remove melting material from contact area of the laser beam together with machining material and ensure protection of lens during cutting. Increasing of the shield gas pressure allows increasing of cutting speed, and it has an impact on the worsened surface roughness [12]. In technical literature [13], there are shown practical experience dealing with evaluation of the laser quality and from the point of view of defects newly-emerge directly in place of the cut.

\section{Design of the experiment}

The experimental part was focused on determination of the cut quality after laser cutting. The evaluation deals with selected surface roughness parameters and with the defects emerging during laser cutting. There were used samples made from soft carbon constructional steel CSN 11375 (S235JR). The dimensions of the samples were $60 \times 30 \mathrm{~mm}$ with thickness $10 \mathrm{~mm}$ and $15 \mathrm{~mm}$. The cuting speed, the shield gas pressure and the focal spor position were changed according to proposal the experimental activity and achieved of the cut quality. The other parameters had the constant value at the whole time of the cutting, see table 2.

Table 2. Designed parameters for laser cutting

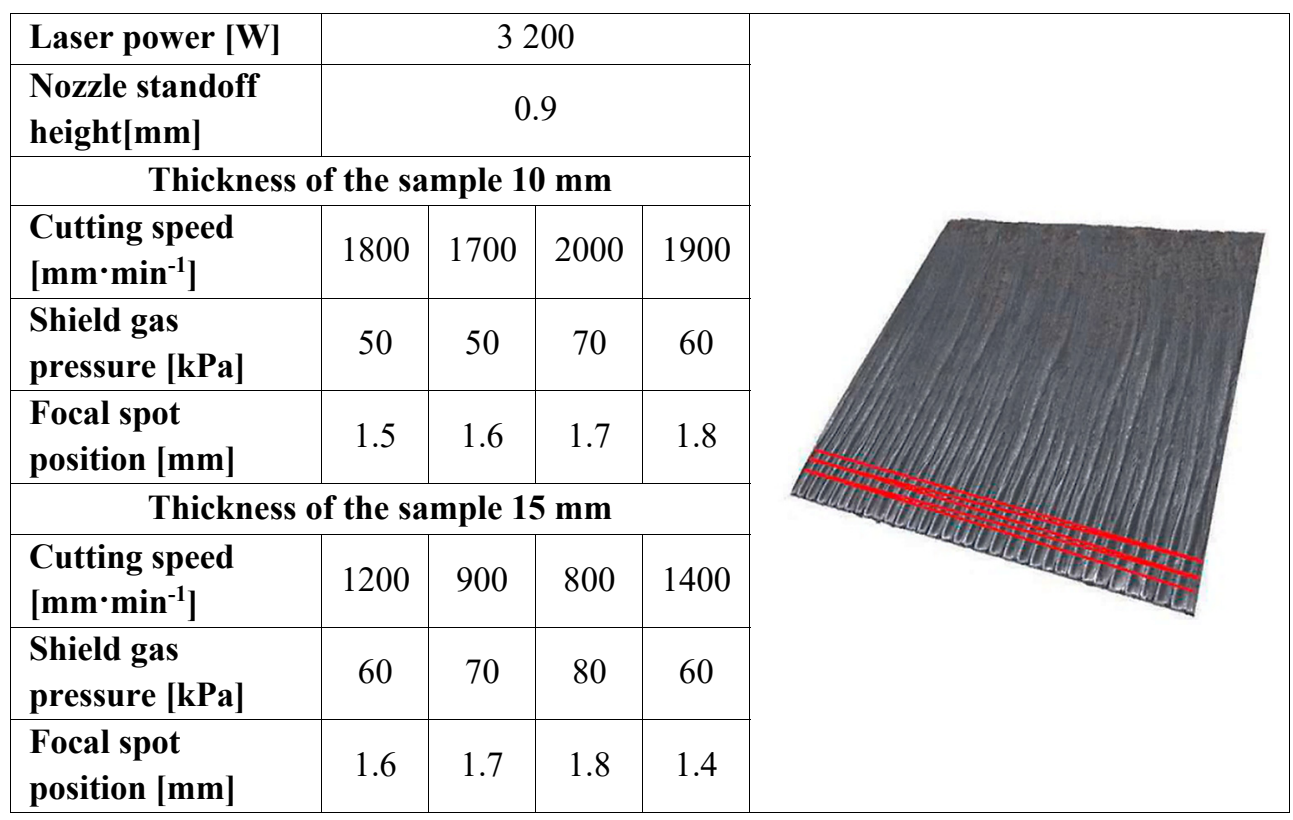

The significant criterion for the evaluation of the cut quality is the surface roughness. There was used optical microscope Alicona InfiniteFocus G5 for its evaluation. The surface measurement was realized out of area of visible defects emerging during laser cutting, such as heating of the cut edge and presence of the burrs. The evaluation of the influence of cut quality was realized in place where visibly came about the biggest influencing of the surface by laser cutting. There were surface roughness parameters Ra, Rq, Rz and the core roughness $\mathrm{Rk}$, reduced peak height Rpk and reduced valley depth Rvk which were determined from material ratio (Abbott-Firestone curve) which were evaluated (fig. 1). 


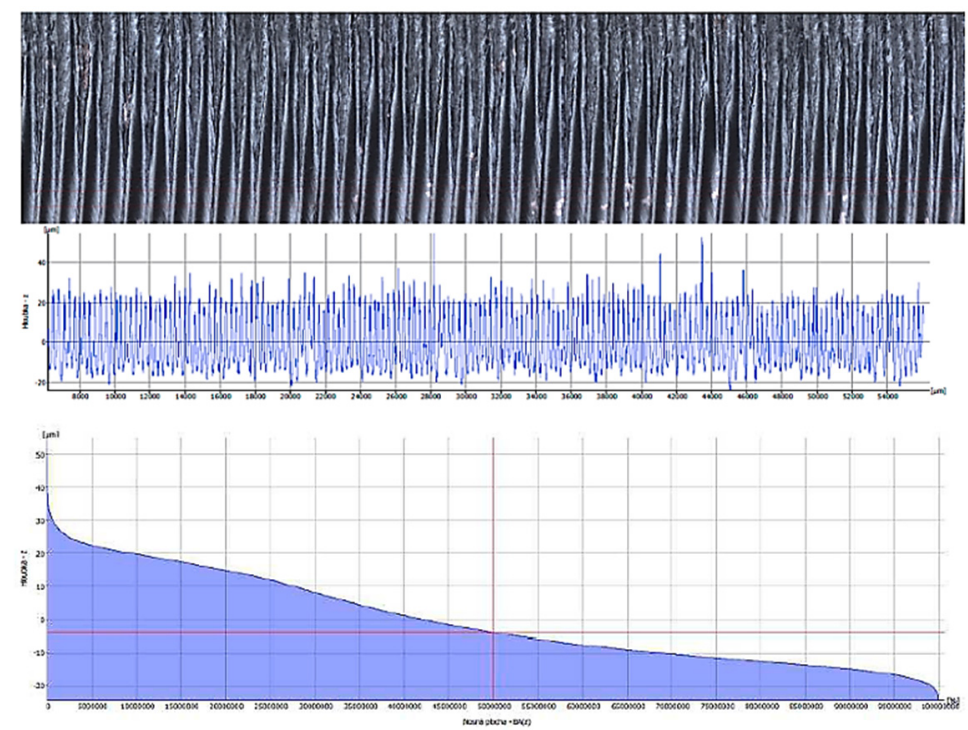

Fig. 1. Example of measurement of the surface quality

\section{The evaluation of cut quality after laser cutting}

Cutting of the samples was realized under pre-determined cutting parameters, the thickness of sample substantially influences cutting process and the final cut quality. There has been proposed lower cutting speed for thick samples to avoid incomplete splitting of the material. The surfaces of cut were composed of the slides (tab. 3) - the scratches in to the surface forming its roughness. The slides were caused by higher cutting speed and occurred more likely on the bottom cut of the edge. The grooves are almost parallel to the direction of the laser beam, and their occurrence is particularly evident in sample no. 3, where the highest cutting speed was used. With increasing speed is created larger slide against direction of the cutting. The selected value of the laser power was sufficient for cutting of the both set of the samples.

The top edge of individual cuts were covered with overhangs which were caused by overflowing material. The cut edge overhang was accompanied by the adherent slag intersecting the cutting area was in the sample no. 7 (larger thickness of the sample). The cause of her origin was high value of the shield gas pressure combined with lower cutting speed. It caused excessive worsening of the cut quality (tab. 3). The surfaces on samples of $15 \mathrm{~mm}$ were created by strong slides again on the bottom sides of the cut which changed into grouped gouges in specific places, especially for samples no. 6 and 7 as a result of set very low cutting speed.

The measured results of the surface roughness of the both sets of samples confirmed that the thickness of cut material has the influence on surface roughness of the cut (tab. 3). For the sample set with smaller thickness $(10 \mathrm{~mm})$, there were measured lower values of the surface roughness. The best results were evaluated for sample no. 2 , there was set the lowest value of cutting speed and the shield gas pressure. For the same sample, there was also measured the lowest value of the core roughness $\mathrm{Rk}$, which it corresponds to the smallest area comprising of the protrusions and the recesses. This confirm that the surface after laser cutting is the least prone to the wear and clinging of impurities on the surface. With increasing values of the input parameters, there came about significant worsening of the surface quality the other cutting 
surfaces. The samples of the thickness $15 \mathrm{~mm}$, there were used much lower cutting speed in comparison with previous set of the samples with regard to total separation of the material. Despite lower input parameters, especially the cutting speed, there wasn't achieved better cut quality. The combination of the larger thickness and smaller cutting speed more than $50 \%$ caused worsened surface roughness of the all cuts. This can observed on the samples no. 6 and no. 7, where the values core roughness Rk acquired very high value confirming surface poor-quality created by strong unevenness. In table, there is shown the values another parameters, such as Rpk - reduced peak height, peak height sticking out above the core roughness, Rvk - reduced valley depth is the depth under the core roughness.

Table 3. The results of the samples with thickness $10 \mathrm{~mm}$ and $15 \mathrm{~mm}$

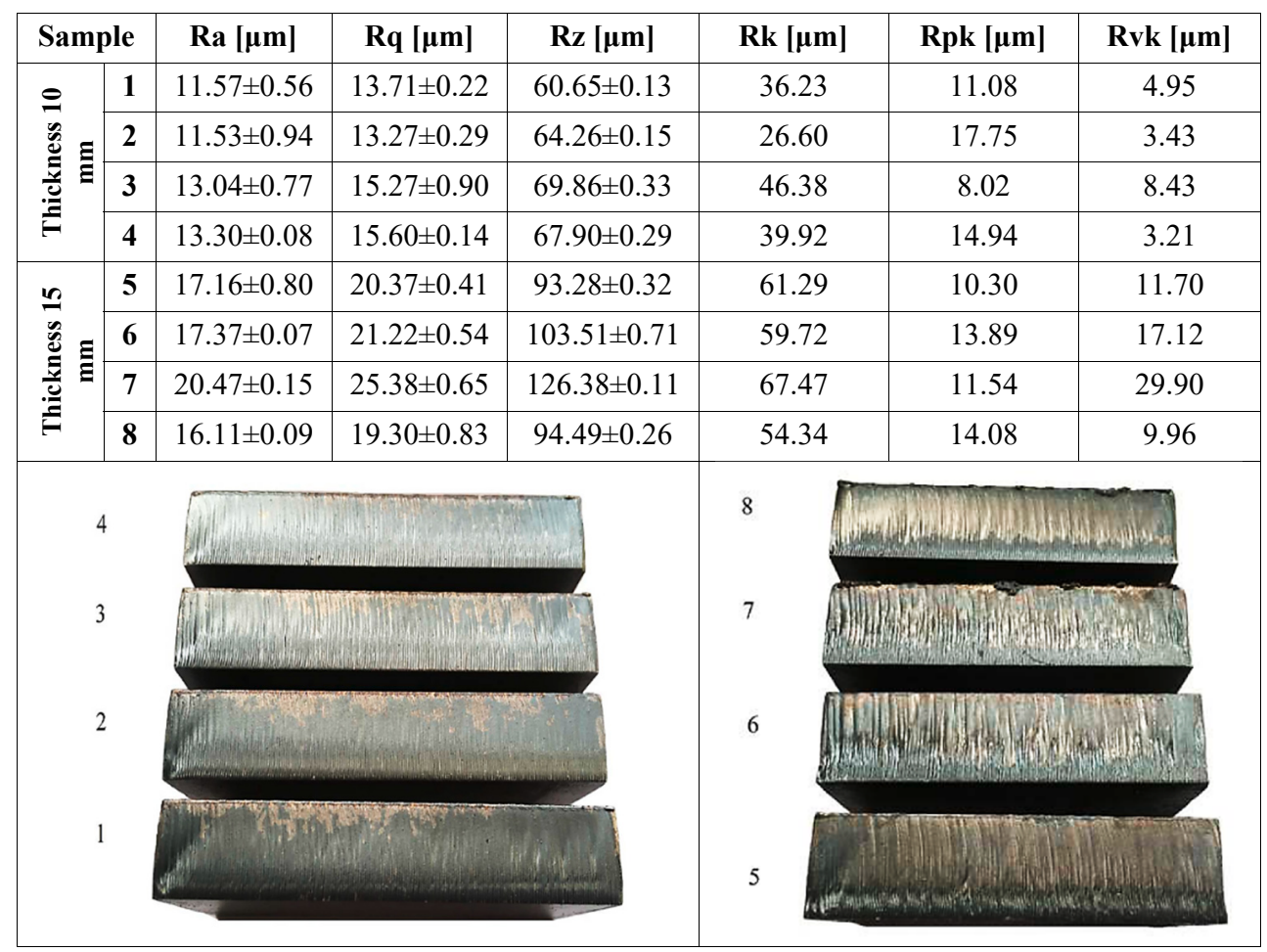

\section{Conclusion}

The experimental activity was focused on the evaluation of the cut quality using laser technology. For realization of the experiment there was designed testing samples with thickness of 10 and $15 \mathrm{~mm}$ which were made from material S235JR and were selected parameters of the laser cutting. The cut quality was evaluated on the basis of the measuring selected surface roughness parameters and selected parameters defined material ratio using optical non-contact microscope Alicona Infinite Focus G5. The cut quality of the surfaces was evaluated on the basis of standard ČSN EN ISO 17 658, which determinates defects emerging after thermal splitting on the material surface.

Not only the choice of material, its thickness but selected parameters of the cutting process have an influence on the surface quality of material after laser cutting. For the experiment, there were set constant laser power and nozzle standoff height apart cut material. The selected parameters, especially cutting speed, were selected with regards to thickness of the material, 
so that was ensured total splitting of the material. Depending on select values of the cutting speed was achieved better results of the surface roughness for set of samples with thickness $10 \mathrm{~mm}$. The best surface roughness was measured for the sample with the lowest cutting speed and the shield gas pressure. This surface achieved required quality and improved resistance against the wear of surface during process. Despite substantially lower set input parameters of laser, the surface for samples with thickness $15 \mathrm{~mm}$ showed strongly worsened roughness and surface quality. The combination of the more than twice the lower cutting speed with shield gas pressure caused poor quality cuts. For these samples, there was measured also high value of the core roughness $\mathrm{Rk}$, which confirmed that the surface is prone to the wear and it created by strong unevenness.

From the point of view of evaluation of surface quality according to standard ČSN EN ISO 17 568, the surfaces were covered with slides, which were caused by higher cutting speed. For the samples with thickness $10 \mathrm{~mm}$, there were the slides mostly parallel with direction of the laser beam. It caused by constant and sufficiently large laser power, where didn't come about delay of the cutting tracks. For the both sets of the testing samples, there were cut edge covered with overhangs caused by overflowing basic material. As a result of of the higher shield gas pressure and the lower cutting speed was created the adherent slag for the samples with thickness $15 \mathrm{~mm}$. The other way around the samples which were cut with the low cutting speed had worsened surface roughness and strong slides. These slides changed gradually into grouped gouges in specific places.

Generally, it can be confirmed that surface quality created either laser technology or other thermal separation is significantly influenced by material thickness and set process parameters. Not always, the setting their high values is achieved request surface quality. Just suitable combination of cut material and input parameters can achieve significantly lower surface roughness and better cut quality. If there will achieve to find of suitable combination for selected cut material, then the surface won't need to finish using by chipping machining and it will have an influence decrease producing time and costs at the total production.

Article has been done in connection with projects Education system for personal resource of development and research in field of modern trend of surface engineering - surface integrity, reg. no. CZ.1.07/2.3.00/20.0037 financed by Structural Founds of Europe Union and from the means of state budget of the Czech Republic and by project Students Grant Competition SP2018/150 and SP2018/136 financed by the Ministry of Education, Youth and Sports and Faculty of Mechanical Engineering VŠBTUO.

\section{References}

1. W. Pakiela, T. Tanski, Z. Brytan, K. Labisz, The influence of laser alloying on the structure and mechanical properties of AlMg5Si2Mn surface layers. Appl. Phys. A Mat. S\&P, 122 (2016)

2. E. Librera, G. Riva, H. Safarzadeh, B. Previtali, On the use of Areal Roughness Parameters to Assess Surface Quality in Laser Cutting of Stainless Steel with CO2 and Fiber Sources. Procedia CIRP, 33, 532-537 (2015)

3. K. Jarosz, P. Loschner, P. Nieslony, Effect of Cutting Speed on Surface Quality and Heataffected Zone in Laser Cutting of 316L Stainless Steel. Proc. Eng., 149, 155-162 (2016)

4. J. Petru, T. Zlamal, R. Cep, K. Monkova, P. Monka, Influence of Cutting Parameters on Heat Affected Zone after Laser Cutting. Tehnicki Vjestnik - Tech. Gaz., 20, 225-230 (2013) 
5. W. Pakiela, T. Tanski, M. Pawlyta, K. Pakiela, Z. Brytan, M. Sroka, The structure and mechanical properties of AlMg5Si2Mn alloy after surface alloying by the use of fiber laser. App. Phys. A., 124 (2018)

6. D. Narovec, Analysis of the surface after laser cutting: Diploma Thesis, 67 (2018)

7. M. Hatala, J. Zajac, R. Cep, I. Orlovsky. Research of the technological parameters importance for plasma arc thermal cutting. In: 2nd ICMAE, 110-116 (2011)

8. M. Tonkovic, Analysis of the material for laser cutting: Dip. thesis, 66 (2014)

9. V. Musil, M. Sadilek, R. Cep, S. Malotova, The influence of cutting parameters on surface quality and nitrogen consumption during laser cutting. MM SJ. 2018, 2363-2366 (2018)

10. Trumpf Werkyeugmaschinen $\mathrm{GmbH}+$ Co. KG. Laser machining: CO2 laser - technical information, 2, 195 (2016)

11. J. Stastny, Connection of mistakes cut with cutting characteristic at laser cutting. Dip. Thesis, 66 (2012)

12. M. Grepl, Study of the Affected Areas of Superalloys Materials after Laser Beam Machining. Dis. thesis, 178 (2015)

13. Trumpf Werkyeugmaschinen $\mathrm{GmbH}+\mathrm{Co}$. KG. Laser processing: CO2 laser-tech. info. 2, 156 (2007) 